\title{
STUDY OF CAUSAL FACTORS OF ROAD ACCIDENTS ON PANIPAT- SAMALKHA SECTION OF NH-1
}

\author{
Shashank Sharma ${ }^{1}$, Naveen Rathee ${ }^{2}$ \\ ${ }^{1,2}$ Deptartment of Civil Engineering, DeenBandhuChhotu Ram University of Science \& Technology, Murthal, Sonipat \\ (Haryana)
}

\begin{abstract}
Road safety is important and has become a major concern now a day. Road accidents stop social and economic development of the society. Accidents trends are on the rise and issues should be addressed. So the study is carried out to examine the causal factors resulting in road accidents on Panipat-Samalkha section of NH-1. The total stretch is divided into 3 stretches i.e Stretch1(Toll-Tax-Sanjaychowk), Stretch -2 (Gohanamor-PoliceLine) and Stretch 3(Jhattipur-Samalkha Flyover). The methodology involves the collection of F.I.R data (2011-2013) from various Police Stations i.ePanipat City (Stretch-1), Chandnibagh (Stretch2), Samalkha (Stretch-3) Police Station \&to identify, survey and analysis the black spot locations based on FIR reports and figure out the type of injuries the road users had gone through from 2011-13 and study out the causal factors which increase the road accidents and then, to suggest preventive measures to reduce number of road accidents. According to study, it is found that, Road traffic crash numbers are on the rise. Major Black spot identified during analysis are NangalKheri, Siwah, Police line, Chokker Petrol Pump, Manana Mor, Bus Stand (Panipat) \& Toll Plaza. The fatality rate in Stretch-1, Stretch-2, Strecth-3 are 34\%, 49\% \& $37 \%$ respectively. Rear end collision \& collision during crossing are the main causes of accident \& the percentage of crashes in Stretch-1 \& Stretch-2 is 52\% \& 59\% resp. The percentage of crashes in Stretch-3 due to Head-on collision is 48\%.(LMV) i.e Cars, jeeps category is now the most involved in crashes; they constitute $26 \%$ of total crashes in Panipat city, $42 \%$ of all crashes in Chandnibagh section and $41 \%$ crashes in Samalkha section. A truck constitutes 20\% of total crashes in Panipat city, 33\% of all crashes in Chandnibagh\& 35\% of crashes in Samalkha section. The main victims of road crashes are VRUs including pedestrians (34.1\%), bikers etc. The spot speeds observed towards higher side of posted speed limits on the stretch resulting more fatalities.
\end{abstract}

Keywords: Causal Factors, Light Motor Vehicles, Vulnerable Road Users.

\section{INTRODUCTION}

Road crashes take away the life causing fatalities around 4,500 people every day. This is a global humanitarian disaster, and it is man-made. (Global Road Safety Partnership Annual Report 2014). ${ }^{[1]}$ The present traffic condition on road is extremely heavy and has almost reached the capacity of the road. It influenced in increase of the number of vehicles and road accidents. It is surprising to know that India has only $1 \%$ of the total world's vehicles which accounts for $16 \%$ of the total world's accidental deaths. ${ }^{[2]}$ The very first Global Status Report on Road Safety by WHO mentioned the mortality on Indian roads is the highest in the world. ${ }^{[3]}$ There is a great need to take up important measures that can help improve road safety and behavior of road users in the country.

\section{Study Area}

In this paper stretch from Panipat L\&T Toll Plaza to NH-1 Samalkha Over-bridge end pointwas selected for the study. Elevated expressway is not included in this research. For local users, 2-lane peripheral road is provided on either side of the elevated expressway.

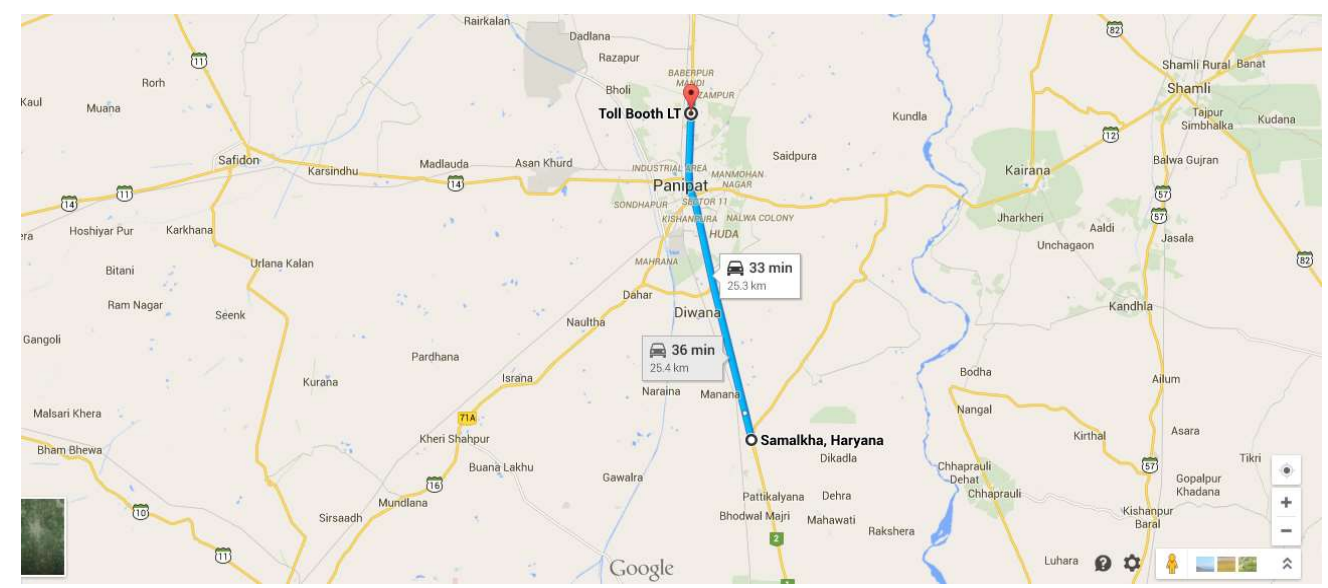

Fig 1: Location Information using google maps 


\section{Objectives}

The objective consists of following:

- To identify, observe, survey and analysis the black spot locations based on FIR reports.

- Figure out the type of injuries the road users had gone through from 2011-13 and draw out the causal factors which increase road accidents.

- To suggest preventive measures to reduce number of road accidents.

\section{Review of Literature}

One article describesthe rank of accident prone areas by accident severity value (ASV) ${ }^{[9]}$. Another article represents the use of Road Accident Investigation (RAI) in planning road traffic safety schemes ${ }^{[10]}$. One article summarized about the causal factors of road traffic crashes in some selected states ${ }^{[11]}$. Other article carried out a road safety audit ${ }^{[13]}$. One article analyzed the road geometrics and find accident prone areas $^{[14]}$.

\section{Methodology}

The total stretch of $25 \mathrm{~km}$ is divided into 3 stretches i.e Stretch-1 is from Toll-Tax to Sanjaychowk $(5.4 \mathrm{~km})$, Stretch 2 is from Sanjaychowk to Police Line $(8 \mathrm{~km})$ and Stretch 3 is from Police Line to Samalkha Flyover $(12 \mathrm{~km})$. The methodology involves the collection of F.I.R data (20112013) from various Police Stations i.ePanipat City (Stretch1), Chandnibagh (Stretch-2), Samalkha (Stretch-3) Police Station \& to identify, survey and analysis the black spot locations based on FIR reports and figure out the type of injuries the road users had gone through from 2011-13 and study out the causal factors which increase the road accidents and then, to suggest preventive measures to reduce number of road accidents.

\section{ANALYSIS OF DATA}

\section{Traffic Volume Study}

It is defined as the procedure to determine mainly volume of traffic moving on the roads at a particular section during a particular time. The Annual average daily traffic (AADT) on $\mathrm{NH}-1$ is $82,543^{[15]}$. Below given fig 3.1 shows traffic composition based on types of vehicles on roads.

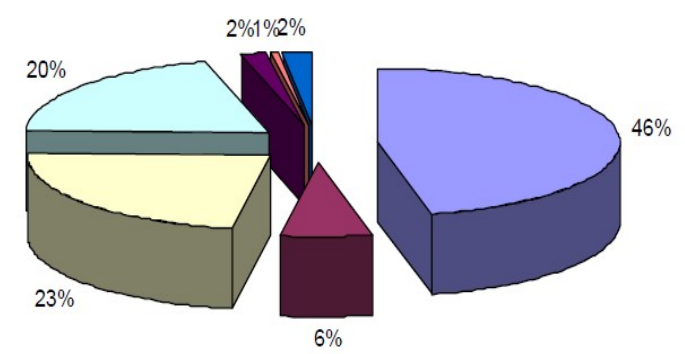

$\square$ Car $\square$ Bus $\square$ Truck $\square$ Two- Wheeler $\square$ Cycle $\square$ Animal Drawn Vehicle $\square$ Others

Fig 2. Traffic Composition based on types of vehicles

\section{Accident data analysis}

The records covered the period of 3 years (2011-2013) data. Accident Rate \& frequency were calculated which is being done to analyze the data and to make recommendations as per the observations.

\section{Accident Rate}

Accident Rate $=\frac{M}{L}$

Where $\mathrm{M}=$ Total no of Accidents of a stretch $\mathrm{L}=$ Length of Road

Table 1. Accident Rate (2011-2013)

\begin{tabular}{|c|c|c|c|c|c|c|c|c|}
\hline \multirow{3}{*}{ Name of the stretch } & \multirow{3}{*}{ Length } & \multirow{3}{*}{ Police Station } & \multicolumn{6}{|c|}{ Number of Accidents } \\
\hline & & & \multicolumn{3}{|c|}{ Total Accident } & \multicolumn{3}{|c|}{ Accident Rate } \\
\hline & & & 2011 & 2012 & 2013 & 2011 & 2012 & 2013 \\
\hline Toll Plaza to Sanjay Chowk & $5.4 \mathrm{Km}$ & Panipat City & 32 & 26 & 40 & 5.92 & 5.81 & 7.40 \\
\hline Sanjay Chowk to Police Line & $8 \mathrm{Km}$ & ChandaniBagh & 58 & 43 & 54 & 7.25 & 5.37 & 6.75 \\
\hline $\begin{array}{c}\text { Police Line to SamalkhaChokker Petrol } \\
\text { Pump }\end{array}$ & $12 \mathrm{Km}$ & Samalkha & 44 & 58 & 48 & 3.66 & 4.84 & 4.0 \\
\hline
\end{tabular}

From the Table 1, it is observed that rate of accident is more for stretch 2 followed by stretch-1 \& 3 respectively in 2011 . In 2012, rate of accident is more for stretch 1 followed by stretch-2 \& 3 respectively. In 2013, rate of accident is more for stretch 1 followed by stretch- $2 \& 3$ respectively.

\section{Annual Variations in Accidents}

It is observed that percentage accidents are increasing relatively in most of the year. In the year 2013 accident rate was high and low in the year 2011.It may be due to increase in no of vehicles, bad traffic environment, and increase in population. 


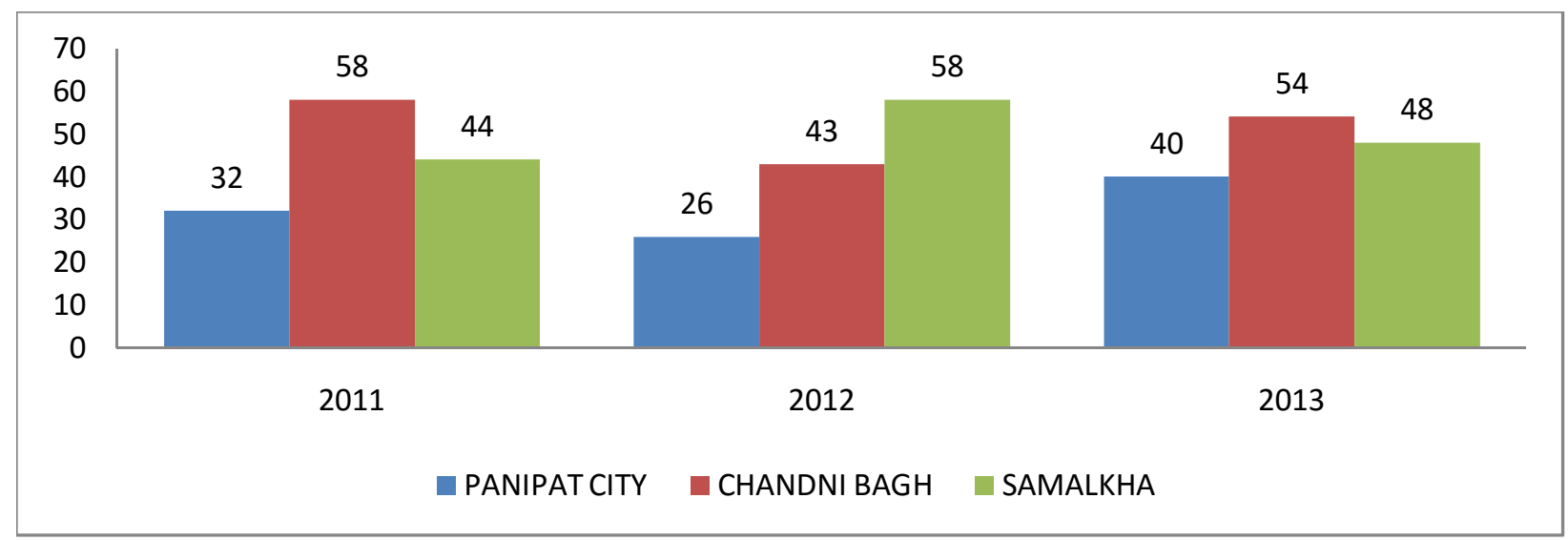

Fig 3: Annual variations in accidents of total stretch

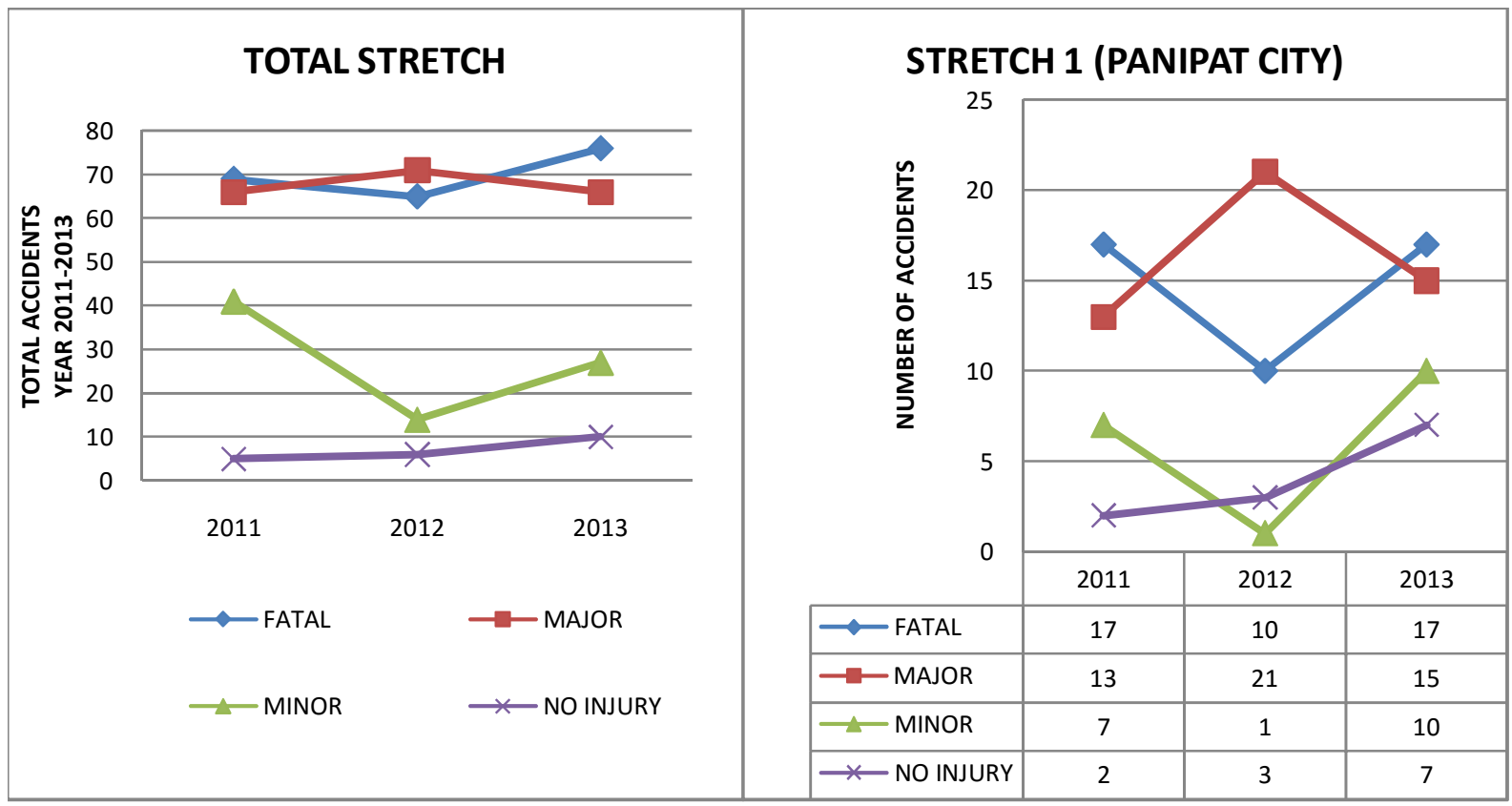

Fig 4. Types of Injuries in total stretch and annual variations in accidents of stretch-1 (Panipat city)

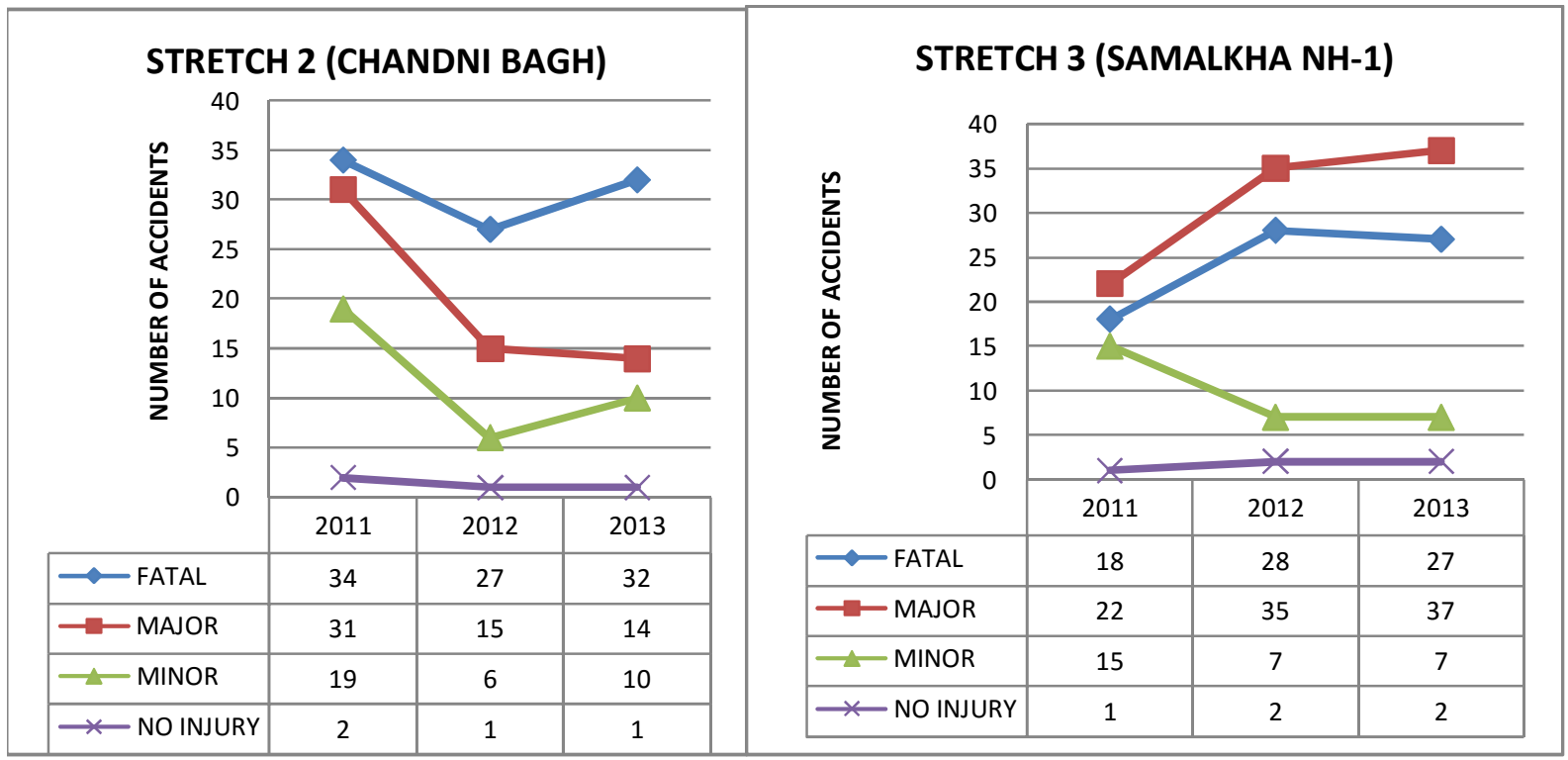

Fig 5. Annual variations in accidents of Stretch-2 (CHANDANI BAGH)\& Stretch-3 (SAMALKHA) 
Fig. 4-5 shows annual variation in accidents of the three stretches. It is observed that no of accidents for Stretch-2 are higher than Stretch -3 followed by Stretch-1.This is because of high traffic volume on stretch 2. Traffic volume decreases on stretch-3 as it is outside the city area \& local traffic is not there. Stretch-2 has high population density as this is the main town of the Panipat City \& many industries are present nearby this stretch. It is also connected with major state highway road coming from Rohtak, Jind and Shamli (U.P). Being the industrial city, accident rate is more due to more no of commercial and noncommercial vehicles on the road, bad traffic environment, error of driver etc. The more fatal $\&$ severe accidents on stretch 2 is due to lack of enforcement on particular places, wrong side driving, pedestrians not using the foot over bridge \& zebra crossing, shortage of traffic control devices \& drivers trying to speed-up the vehicle as they leave the city.

\section{Month wise Accident Comparison}

Fig 6 shows the month wise accident comparison of Stretch1 (Panipat City). It was observed that more number of accident in August \& September. This is due to environment change, bad lighting, fatigue, inconvenient heat \& water logging due to pre monsoon showers.

Fig 7 shows the month wise accident comparison of Stretch2 (ChandniBagh). It was observed that more number of accident inJune and January. This is due to environment change, bad lighting, fatigue, inconvenient heat \& water logging due to pre monsoon showers.

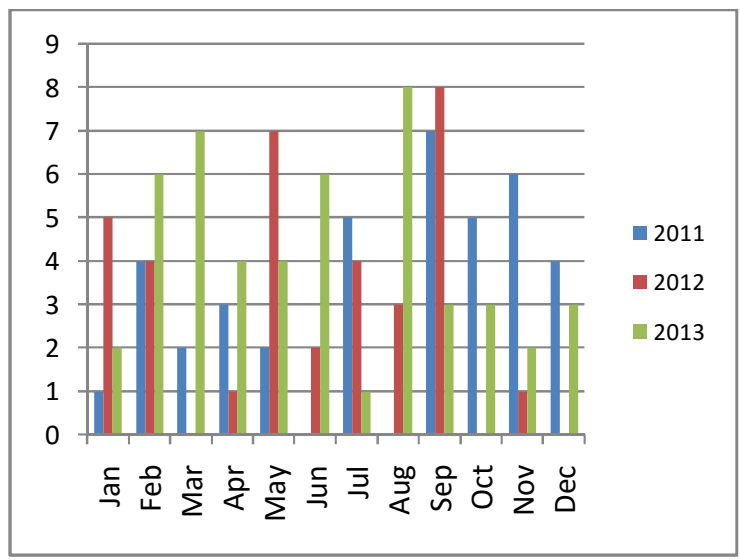

Fig 6. Monthly variations in accidents of Stretch-1 (PANIPAT CITY)

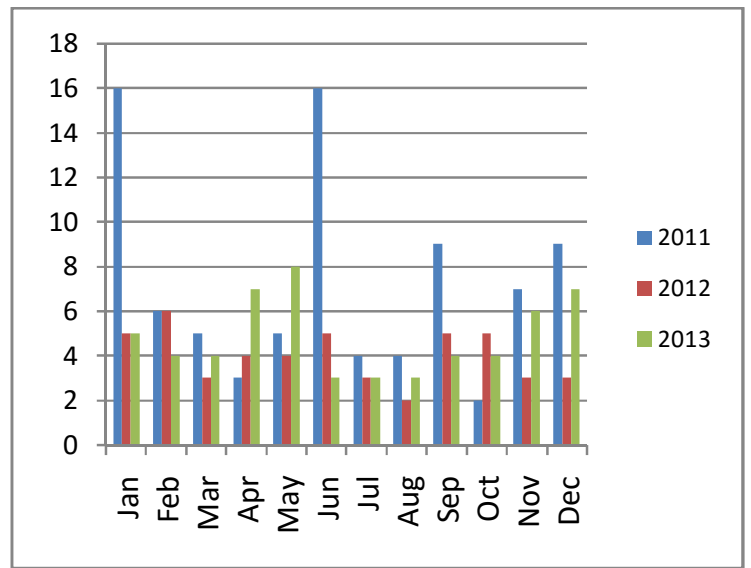

Fig 7: Stretch-2 (CHANDNI BAGH)

Fig 8 shows the monthly variation in accidents of Stretch-3 (Samalkha). ). It was observed that more number of accident in August. This is due to environment change, bad lighting, fatigue, inconvenient heat \& water logging due to pre monsoon showers.

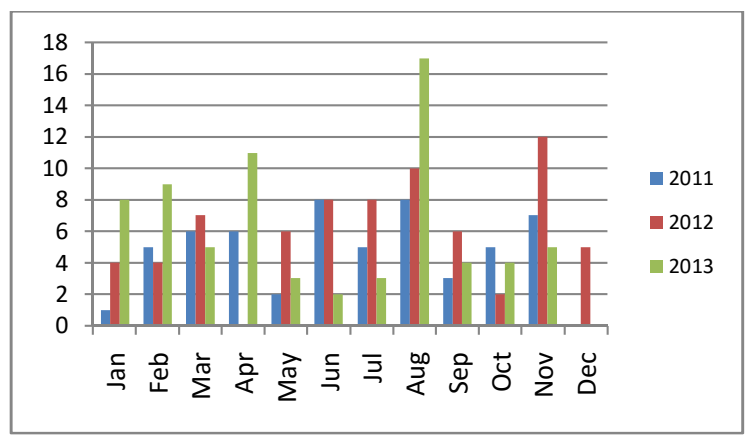

Fig 8. Monthly variations in accidents of Stretch-3 (SAMALKHA)

\section{Involving of vehicles in accident}

As per the pie chartshows that $26 \%$ for car drivers, $21 \%$ for bus driver, $20 \%$ for truck drivers, $14 \%$ for unknown driver $\& 14 \%$ for 2 wheelers andthe stretch-2 pie chart shows that $42 \%$ for car drivers, $33 \%$ for truck driver, $10 \%$ for unknown drivers, $5 \%$ for bus driver $\& 4 \%$ for 2 wheelers as shown in fig.9. Truck drivers consume alcohol and drugs in long driving. Due to which more number of accidents occurs.
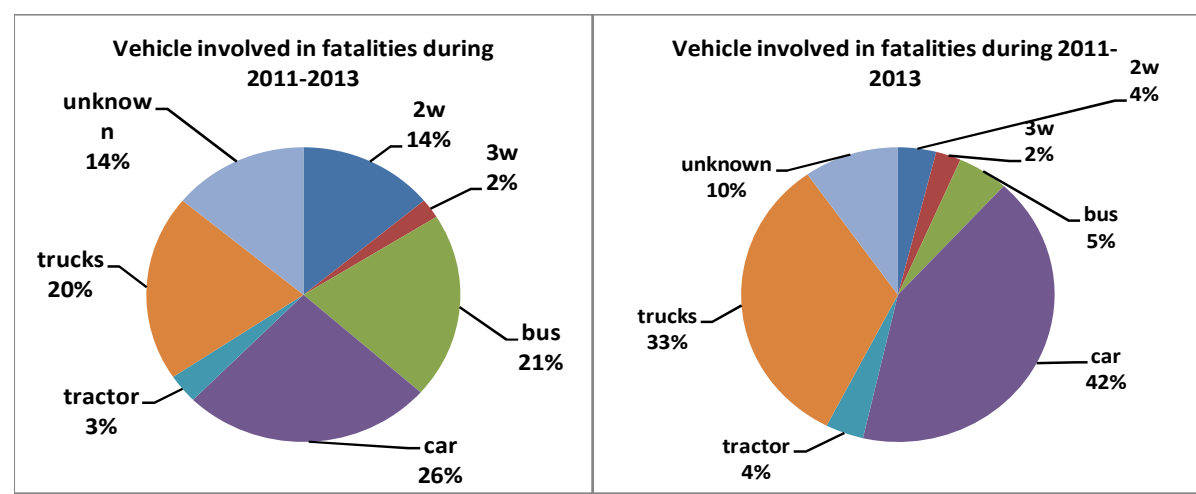

Fig 9. Vehicle involved in fatalities during 2011-2013 Stretch-1 (Panipat City) and Stretch-2 (ChandniBagh) 
The below pie chart shows that $41 \%$ of fatalities by car drivers, $35 \%$ by truck driver, $7 \%$ by bus driver $\&$ by two wheelers , $3 \%$ by unknown drivers as shown in fig.4.10.

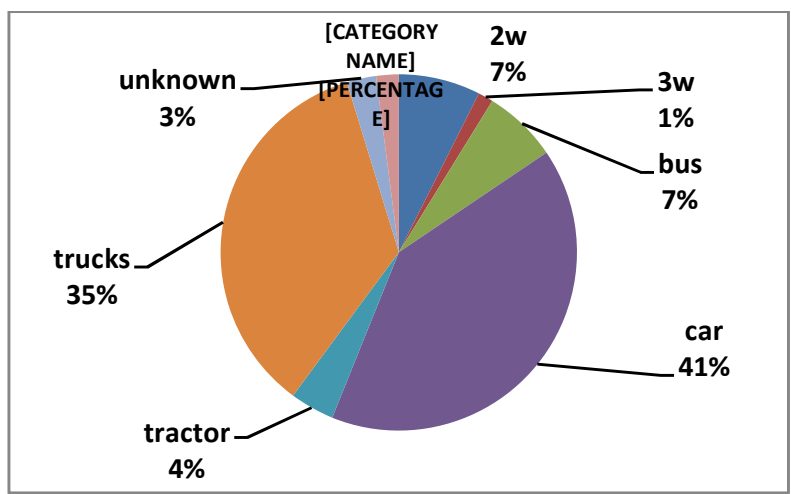

Fig 10. Vehicle involved in fatalities during 2011-2013 Stretch-3 (Samalkha)

\section{Victims}

Victims due to hitting of vehicles during 2011-2013 in Panipat City are shown below. The results indicate that 55 percent are VRU's followed by 21 percent by Car users, 6 percent are 3 wheelers, 4 percent are Truck users, 2 percents are Tractors and 1 percent are bus users as shown in fig.11.The fig12 pie chart shows the victims in Chandnibagh area during 2011-2013. The results indicate that 81 percent are VRU's followed by 10 percent of Car users, 5 percent are 3 wheelers, 2 percent are Truck users, 1 percents are Tractors and 1 percent are bus users.

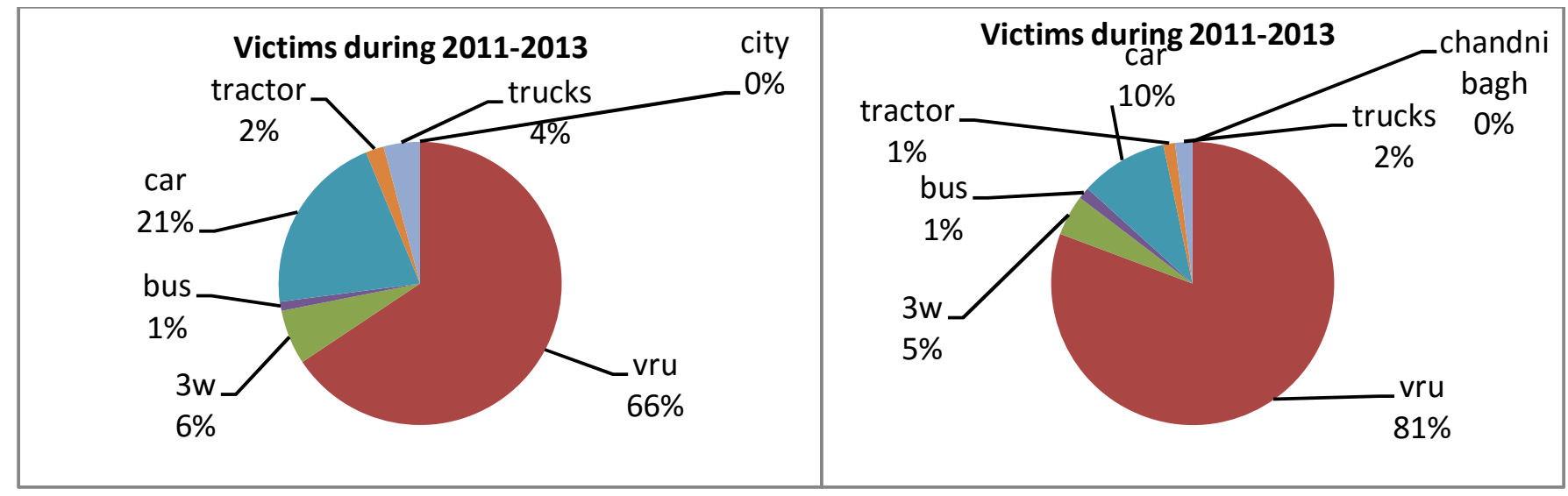

Fig 11. Victims during 2011-2013 Stretch -1(Panipat City) and Fig 12. Stretch-2 (Chandnibagh)

The above pie chart shows the victims in Samalkha area during 2011-2013. The results indicate that 78 percent are VRU's followed by 11 percent of Car users, 5 percent are trucks, 3 percent are three wheelers and 3 percents are Tractors as shown in fig. 12 .

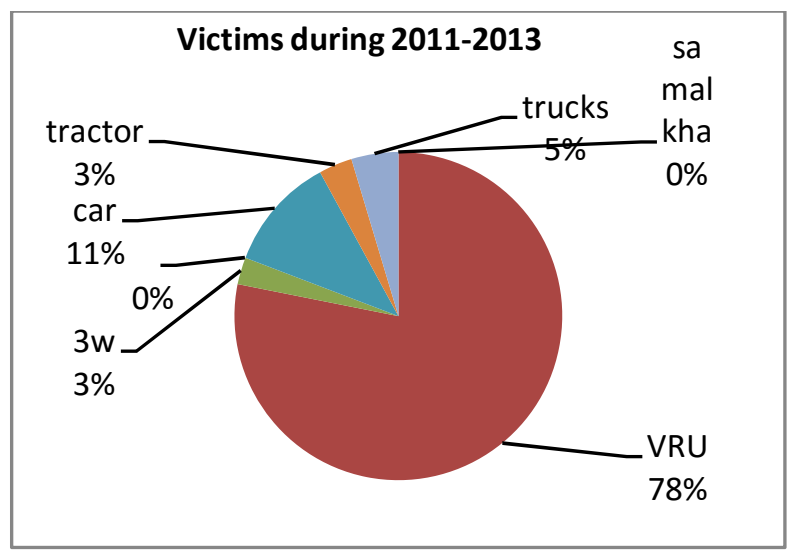

Fig 12. Victims during 2011-2013 Stretch-3 (Samalkha)

\section{Observations}

- Field observations indicated a fair degree of proper use of road safety measures and facilities provided on the highway. Generally pedestrians used the walkways, shoulders and crossing points especially within the divided dual carriageway section 6-lane highway from Siwah to Samalkha.It was noted that few vehicles gave way to the pedestrians at the designated crossings. Due to the low vehicle speeds within the city, pedestrians are able to identify gaps which allow them to cross conveniently.

- It was also observed that a number of road signs and road studs (cat eyes) are either damaged, defaced or vandalized. Flattening deformation of medians is prevalent in most places and has rendered the medians less effective. The ramps of the speed tables were also observed to be fast deteriorating. A number of pedestrian crossing markings are faded.

- After analysis of the accident data, 6 black spots are identified which are having maximum concentration of accidents. Toll-plaza constitutes 26 accidents (6.45\%), Manana intersection constitutes 20 accidents (5\%), Police line intersection constitutes 31 accidents (7.69\%), Nangal-Kheri intersection constitutes 18 accidents (4.46\%), Siwah intersection constitutes 27 accidents $(6.69 \%)$, Chokker petrol pump constitutes 17 accidents $(4.21 \%)$. 


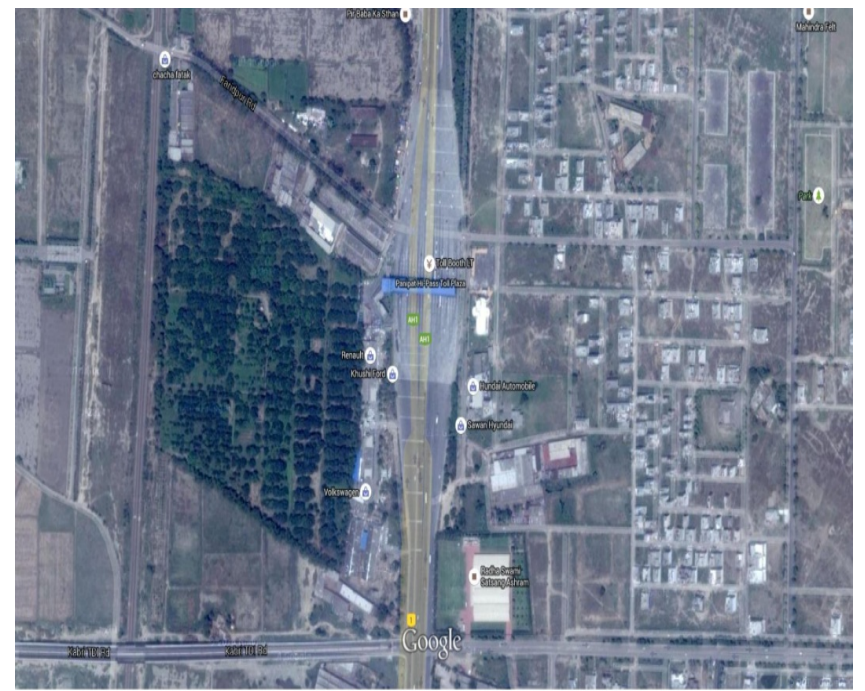

Fig.13- Google map of Toll-Plaza Panipat

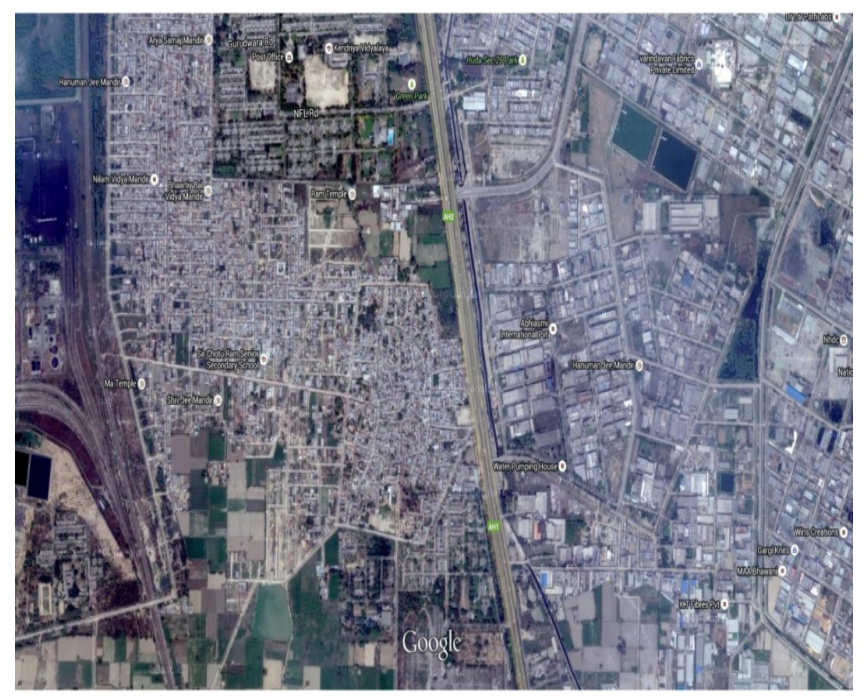

Fig.14- Google map of Nangal-KheriIntersection,Panipat

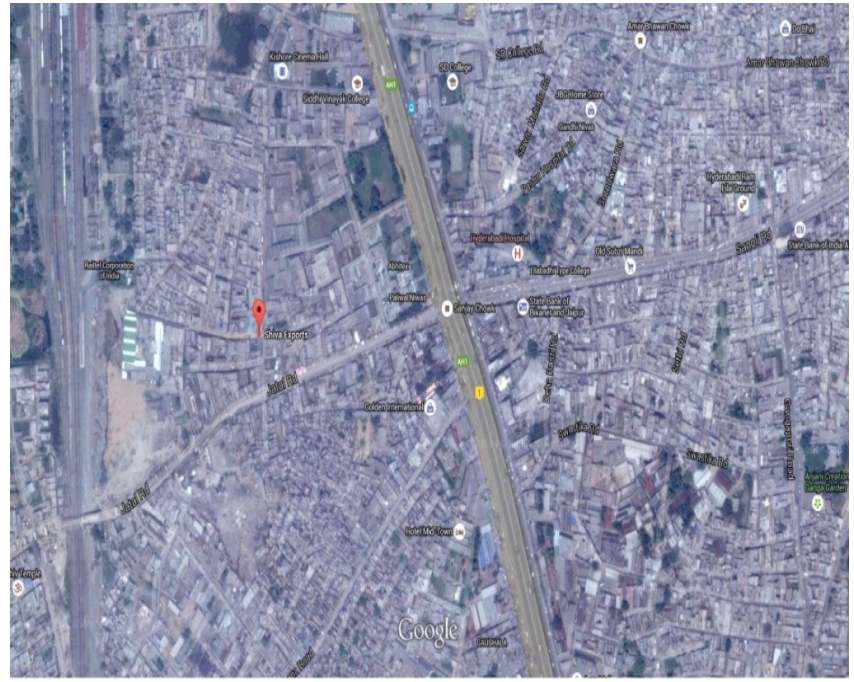

Fig.15- Google map of Siwah Intersection, Panipat

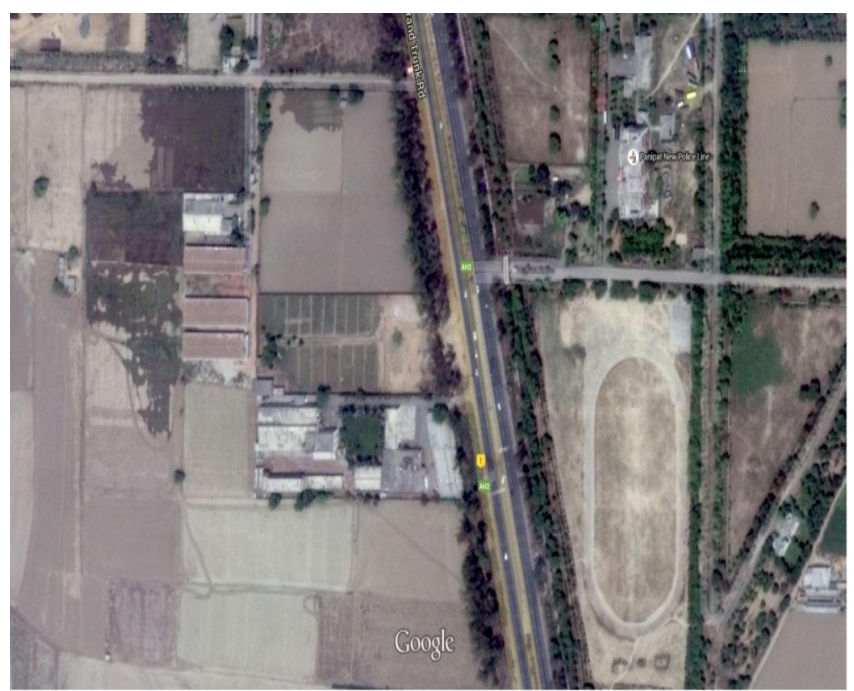

Fig.16-Google map of Police Line Intersection, Panipat

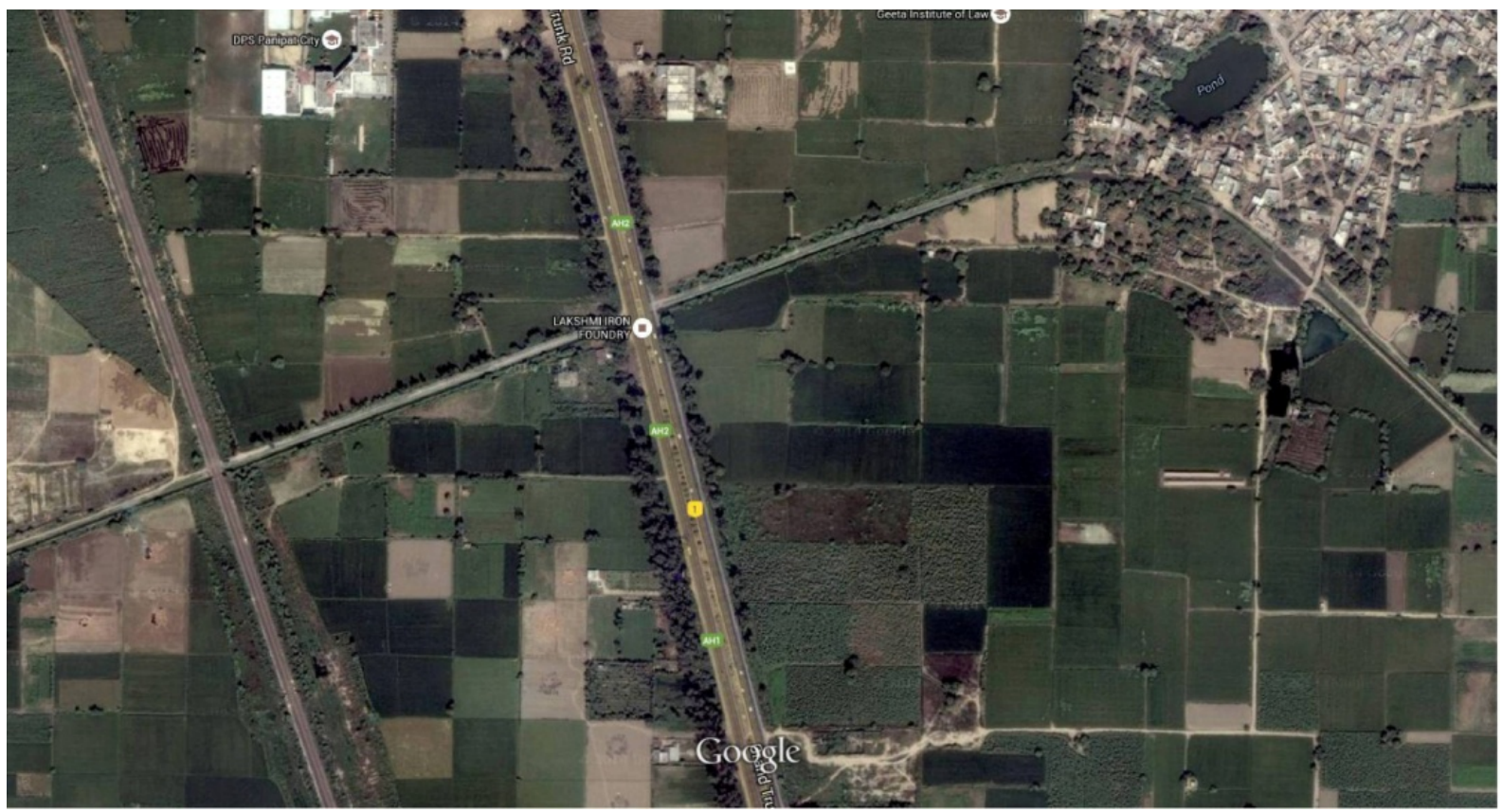

Fig17-Google map of Manana Intersection, Panipat 


\section{CONCLUSION}

After analyzed the study, the following points may be drawn:

1. Road traffic crash numbers on various sections found increasing.

2. The Sanjay Chowk to Police Line (ChandniBagh) section is the major contributor to the increase in crashes.

3. The fatality rate in Stretch-1, Stretch-2, and Stretch-3 are $34 \%, 49 \%$ and $37 \%$ respectively.

4. Major Black spot locations identified during analysis are NangalKheri, Siwah, Police line, Chokker Petrol Pump, Manana Mor and Toll Plaza.

5. Rear end collision and collision during crossing are the main causes of accident at Bus Stand Panipat, NangalKheri, Siwah and Police line.

6. Head-On collision is the main cause of accident at Chokker petrol pump and Manana Mor.

7. Rear-end collisions are more in Panipat area (Stretch-1) and Chandnibagh area (Stretch-2) and the percentage of crashes due to Rear-End collisions in Stretch-1 and Stretch-2 is $52 \%$ and $59 \%$ respectively.

8. Head-on collisions are more in Samalkha area (Stretch3) with percentage of total crashes as high as $48 \%$.

9. Car and trucks are found to be the most dominant class causing crash casualties. Light motor vehicle (LMV) i.e Cars, jeeps category is now the most involved in crashes; they constitute $26 \%$ of total crashes in Panipat city , $42 \%$ of all crashes in Chandnibagh section and $41 \%$ crashes in Samalkha section. Trucks constitute $20 \%$ of total crashes in Panipat city, $33 \%$ of all crashes in Chandnibagh\& $35 \%$ of crashes in Samalkha section.

10. The main victims are found to be VRU's and the percentage is $66 \%, 81 \%, 78 \%$ in Panipat City, Chandnibagh and Samalkha respectively.

11. The $85^{\text {th }}$ percentile speeds for Stretch-1, Stretch-2, Stretch-3 was found to be $70 \mathrm{~km} / \mathrm{h}, 107 \mathrm{~km} / \mathrm{h}$ and 108 $\mathrm{km} / \mathrm{h}$ respectively. The speed at Stretches 2 and 3 was much higher than the posted speed limit of $90 \mathrm{~km} / \mathrm{h}$ leading to more fatal and severe accidents over these stretches.

\section{RECOMMENDATIONS}

From the findings of this study, the following recommendations are made:

1. High enforcement by the traffic department is required to minimize the accidents at the main Black spots.

2. Traffic official must be available all the time at the busiest intersections i.e Bus stand, Siwah, NangalKheri, Police line and Manana Mor.

3. The Sanjay Chowk - Police Line section should be classified as an urban road and speed limit should be 35$55 \mathrm{~km} / \mathrm{h}$ with the traffic lights at the intersection

4. Encroachment on the road side should be removed to reduce accidents of the pedestrians in the Stretch- 1 .

5. Road must have proper reflectors in all the 3 Stretches so as to avoid accidents.
6. While crossing road, pedestrians must be encouraged to cross the road either using foot-over bridge or zebra crossings at NangalKheri intersection.

7. Optimize the signal coordination at GohanaMor (Stretch2) \&Insar bazaar Red light (Stretch-1).

8. Proper marking and lightening should be provided at all intersection namely NangalKheri, Police line, Siwah, Manana Mor, Chokker petrol pump.

9. The Posted speed Limit of $90 \mathrm{~km} / \mathrm{h}$ must be enforced at Police line, Manana Mor intersection so that accidents due to over speeding can be controlled.

\section{REFERENCES}

[1] Global Road Safety Partnership Annual Report 2014, pp. 10-13.

[2] Punetha, D., Kumar, D. and Mehta, V. (2012) 'Design and Realization of the Accelerometer based Transportation System', International Journal of Computer Applications, vol. 49, no. 15, pp. 17-20.

[3] Sharma, D., Singh, S. and Mukherjee, S. ( 2011) 'A study on road traffic accidents in Anand-Gujarat', healthline ISSN 2229-337X, vol. 2, no. 2,pp. 12-15.

[4] Transport Research Wing, Ministry of Road Transport and Highways. Road Accidents in India 2011. New Delhi: Ministry of Road Transport and Highways, Government of India; 2012.

[5] SensarmaKuntal, BalaniNimmi, Rawat S S, "Road Accidents in India, 2009”, 2011.

[6] Road Accidents in India 2012, Ministry of Road Transport \& Highways Govt. Of India.

[7] Haryana, Arihant Publications, pp 153.

[8] http://traffic.haryanapolice.gov.in/accidentdata.html.

[9] GouravGoel, S.N. Sachdeva, 2012, "Identification of Accident Prone Locations Using Accident Severity Value on a Selected Stretch of NH-1", International Journal of Engineering Research and Applications (IJERA), ISSN: 2248-9622, vol. 3, pp. 31-34.

[10] PIARC - Road Accident Investigation Guidelines for Road Engineers, (August 2007).

[11] Aworemi, Joshua Remi, Abdul-Azeez, IbraheemAdegoke, Olabode, SegunOluwaseun, 2010, "Analytical study of the causal factors of road traffic crashes in south-western Nigeria", International Research Journals Educational Research Vol. 1(4) pp. 118-124 May 2010.

[12] B. Srinivas Rao E. Madhu, Santosh Jalihal T.S. Reddy, Accident Study on National Highway - 5 Between Anakapalli To Visakhapatnam, (2005), Proceedings of the Eastern Asia Society for Transportation Studies, Vol. 5, pp. 1973 - 1988, 2005.

[13] Road safety audit: Development of an accidental model for Urban area (C) 2014 IJEDR | Volume 2, Issue 2 | ISSN: 2321-9939

[14] Road Safety Audit : IOSR Journal of Mechanical and Civil Engineering (IOSRJMCE)

[15] Preparation of Sub Regional Plan for Haryana SubRegion of NCR-2021: Interim Report II. 